TITLE:

\title{
Atomic-level Pd-Au alloying and controllable hydrogen-absorption properties in size-controlled nanoparticles synthesized by hydrogen reduction
}

\section{$\operatorname{AUTHOR}(S)$ :}

Kobayashi, Hirokazu; Yamauchi, Miho; Ikeda, Ryuichi; Kitagawa, Hiroshi

\section{CITATION:}

Kobayashi, Hirokazu ... [et al]. Atomic-level Pd-Au alloying and controllable hydrogenabsorption properties in size-controlled nanoparticles synthesized by hydrogen reduction. Chemical Communications 2009, 32: 4806-4808

\section{ISSUE DATE:}

2009

URL:

http://hdl.handle.net/2433/87373

\section{RIGHT:}

c Royal Society of Chemistry 2009.; This is not the published version. Please cite only the published version.; この論文は出版社版でありませ ん。引用の際には出版社版をご確認ご利用ください。 


\title{
Atomic-Level Pd-Au Alloying and Controllable Hydrogen-Absorption Properties in Size-Controlled Nanoparticles Synthesized by Hydrogen Reduction Method $\dagger$
}

\author{
Hirokazu Kobayashi, $\ddagger^{a}$ Miho Yamauchi $\S^{a b}$ and Hiroshi Kitagawaף $\rrbracket^{* a, c}$ \\ ${ }_{5}$ Received (in $\left.X X X, X X X\right)$ Xth $X X X X X X X X X 200 X$, Accepted Xth $X X X X X X X X X 200 X$ \\ First published on the web Xth $X X X X X X X X X 200 X$ \\ DOI: $10.1039 / b 000000 x$
}

\begin{abstract}
Size-controlled atomic-level Pd-Au alloy nanoparticles have been synthesized with a wide range of atomic raios by a facile method 10 using $\mathbf{H}_{2}$ gas, and their controllable hydrogen-absorption properties have been studied from hydrogen pressurecomposition isotherms and solid-state ${ }^{2} \mathrm{H}$ NMR spectra.
\end{abstract}

Bimetallic nanoparticles have attracted great interest as magnetic, ${ }^{1}$ optical $^{2}$ and catalytic materials ${ }^{3}$ in many fields of 15 science and technology due to their unique and different properties from those of the monometallic nanoparticles. Pd$\mathrm{Au}$ bimetallic nanoparticles are the significant systems, and they play an important role as the effective catalysts in the direct synthesis of hydrogen peroxide from $\mathrm{H}_{2}$ and $\mathrm{O}_{2}$, the 20 hydrodesulfurization of thiophene, the oxidation of alcohols to aldehydes, etc. The enhanced performance can directly be attributed to the synergistic effects of Pd-Au alloying. Due to the wide applications of these Pd-Au catalysts, it is of great interest to study the structure of the bimetallic nanoparticles. ${ }_{25}$ Various phase-separated structures such as core/shell ${ }^{4}$ or cluster-in-cluster, ${ }^{5}$ or alloy structures ${ }^{6}$ have been reported. On the other hand, a few reports are there on the solid-solution structured alloy nanoparticles ${ }^{7}$ where $\mathrm{Pd}$ and $\mathrm{Au}$ are homogeneously mixed at the atomic level. Most of the Pd-Au 30 nanoparticles reported were supported on carbon, activated carbon, or $\mathrm{Al}_{2} \mathrm{O}_{3} \cdot{ }^{7 \text {-e }} \mathrm{A}$ limited number of the reports regarding on the solid-solution nanoparticles originates from the fact that Pd and Au are hard to mix at the atomic level due to their segregation tendency. ${ }^{8}$ The further development of a 35 facile and effective synthesis method for the size-controllable solid-solution Pd-Au nanopartcles is, therefore, still required for technical applications with high efficiency and performance.

In this study, we have synthesized size-contorolled solid40 solution alloy nanoparticles where $\mathrm{Pd}$ and $\mathrm{Au}$ are homogeneously mixed at the atomic level with a wide range of atomic ratios by the successive method using $\mathrm{H}_{2}$ gas as a reducing agent (Fig. 1). A detailed investigation of the structure of the Pd-Au nanoparticles was carried out using

45 high-resolution transmission electron microscopy (HRTEM), energy dispersive spectra (EDS) and powder X-ray diffractions (XRD). Moreover, we have studied the hydrogenabsorption properties of the $\mathrm{Pd}-\mathrm{Au}$ nanoparticles from hydrogen pressure-composition (PC) isotherms and solid-state ${ }_{50}{ }^{2} \mathrm{H}$ NMR spectra.

Poly( $N$-vinyl-2-pyrrolidone) (PVP)-protected Pd

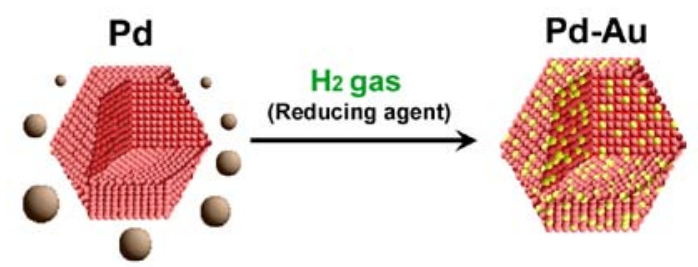

Fig. 1 Schematic view of as-made Pd-Au solid-solution nanoparticles during the successive reduction. (brown ; $\mathrm{Au}^{3+}$, red ; Pd, yellow ; $\mathrm{Au}$ )

nanoparticles were prepared from the alcoholic reduction of ${ }_{55}$ palladium chloride $\left(\mathrm{PdCl}_{2}\right)$ in presence of $\mathrm{PVP} .{ }^{9}$ The aqueous solution of tetrachloroauric acid $\left(\mathrm{HAuCl}_{4}\right)$ was added to the thus-obtained Pd nanoparticles, with a diameter of $7.1 \mathrm{~nm}$, and the mixture was vigorously stirred under $\mathrm{H}_{2}$ gas. The atomic ratio of $\mathrm{Pd}$ and $\mathrm{Au}$ depends on the $\mathrm{HAuCl}_{4}$ 60 concentration.

The atomic ratios of Pd and Au were determined by ICPMS spectrometry, and the corresponding particles were characterized, $\mathrm{Pd}_{80}-\mathrm{Au}_{20}, \mathrm{Pd}_{50}-\mathrm{Au}_{50}$ and $\mathrm{Pd}_{20}-\mathrm{Au}_{80}$. From the results of TEM measurements (Fig. S1 in ESI $\dagger$ ), the 65 corresponding mean diameters of the nanoparticles were $8.4 \pm$ 1.6, $9.1 \pm 1.7$ and $10.1 \pm 2.3 \mathrm{~nm}$, respectively, and the size increased with the additional Au content. From the intensity and position of the surface plasmon resonance peak observed in the ultraviolet-visible absorption spectra for various Pd-Au 70 nanoparticles (Fig. S2 in ESI†), we confirmed the incorporation of Au atoms into Pd nanoparticles. All the Pd$\mathrm{Au}$ nanoparticles showed the XRD patterns from a single face-centered-cubic (fcc) lattice (Figs S3a, S3b in ESI $\dagger$ ). The diffraction peaks of Pd-Au nanoparticles shifted linearly to 75 the lower-angle side with increasing Au content in the Pd-Au nanoparticles in agreement with the larger unit cell parameter for Au (Fig. S3c in ESI†). These results strongly support the formation of the atomic-level Pd-Au alloy over the whole inside the particle.

80 In order to investigate the distribution of $\mathrm{Pd}$ and $\mathrm{Au}$ atoms inside the nanoparticle, HRTEM images and EDS spectra were measured for the $\mathrm{Pd}_{80}-\mathrm{Au}_{20}$ and $\mathrm{Pd}_{50}-\mathrm{Au}_{50}$ nanoparticles, as shown Figs 2a, 2c and Figs 2b, 2d, respectively. In general, each domain (phase separation) structure of Pd and Au such as 85 a core/shell type is observable in the HRTEM image due to the difference in contrast between Pd and Au atoms. ${ }^{4 a-d}$ The difference of such a contrast is not seen in Figs 2a and 2b, 

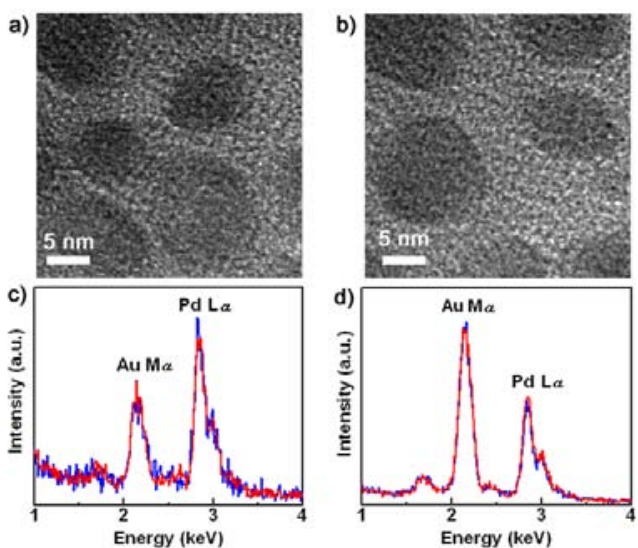

Fig. 2 HRTEM images and EDS spectra in (a) $\mathrm{Pd}_{80}-\mathrm{Au}_{20}$ and (b) $\mathrm{Pd}_{50^{-}}$ $\mathrm{Au}_{50}$ nanoparticles. The analysis was performed for the surface part (blue line) and center part (red line) with a $1 \mathrm{~nm}$ electron beam.

indicating that the structure of the obtained $\mathrm{Pd}-\mathrm{Au}$ 5 nanoparticles is not phase-separated structure of $\mathrm{Pd}$ and $\mathrm{Au}$. In the EDS spectrum for the $\mathrm{Pd}_{80}-\mathrm{Au}_{20}$ nanoparticle (Fig. 2c), the $\mathrm{X}$-ray emission lines from both $\mathrm{Pd} \mathrm{L} \alpha$ and $\mathrm{Au} \mathrm{M} \alpha$ were observed inside one nanoparticle, the difference between the intensity ratios of $\mathrm{Pd} \mathrm{L} \alpha / \mathrm{Au} \mathrm{M} \alpha$ in the surface and the center ${ }_{10}$ parts was not observed. From these results, it was revealed out that the obtained Pd-Au nanoparticles form a homogeneous solid solution alloy, where Pd and Au are mixing at the atomic level. The EDS spectrum for $\mathrm{Pd}_{50}-\mathrm{Au}_{50}$ nanoparticles also showed the similar result to the $\mathrm{Pd}_{80}-\mathrm{Au}_{20}$ nanoparticle; $\mathrm{Pd}$ 15 and $\mathrm{Au}$ atoms are homogeneously distributed in the nanoparticle (Fig. 2d). The atomic ratios of $\mathrm{Pd}$ and $\mathrm{Au}$ for $\mathrm{Pd}_{80}-\mathrm{Au}_{20}$ and $\mathrm{Pd}_{50}-\mathrm{Au}_{50}$ nanoparticles were estimated by the EDS spectra to be $86: 14$ and $50: 50$, respectively, and are consistent with the molar ratios determined by ICP-MAS. 20 Similarly, the distributions of $\mathrm{Pd}$ and $\mathrm{Pt}$ have been investigated for several particles and showed the same results that the intensity ratios of $\mathrm{Pd} \mathrm{L} \alpha / \mathrm{Au} \mathrm{M} \alpha$ were equal.These results indicate the occurrence of $\mathrm{Pd}-\mathrm{Au}$ alloying at the atomic level. It is well known that $\mathrm{H}$ atoms are generated on the 25 surface of $\mathrm{Pd}$ metal from $\mathrm{H}_{2}$ gas and the $\mathrm{H}$ atoms are very active (the so-called nascent hydrogen) and therefore have high reducing ability. The formation of $\mathrm{Pd}-\mathrm{Au}$ alloy is considered to originate not from the replacement between Pd and $\mathrm{Au}^{3+}$ but from the hydrogen reduction. ${ }^{10}$

30 It is also well known that hydrogen molecules can easily invade inside metal or alloy lattices as hydrogen atoms, and generate the defect structures with superabundant vacancies, leading to the atomic rearrangements of alloys. ${ }^{11}$ The formation of the Pd-Au atomic-level alloy can be explained as 35 follows. First, $\mathrm{Au}^{3+}$ is reduced near the $\mathrm{Pd}$ surface by hydrogen, and the $\mathrm{Au}$ atoms diffuse into the inside of $\mathrm{Pd}$ nanoparticles owing to hydrogen-induced vacancies or lattice defects over the entire structure. Consequently, Pd and Au are mixing at the atomic level. Hydrogen gas is considered to 40 work as a double reagent to reduce $\mathrm{Au}^{3+}$ ions to $\mathrm{Au}$ atom and form vacancies, resulting in Pd-Au atomic level alloys.

Studies of hydrogen-absorption properties of the nanoparticles give important information related to the structure and the electronic state. ${ }^{12}$ In order to investigate the

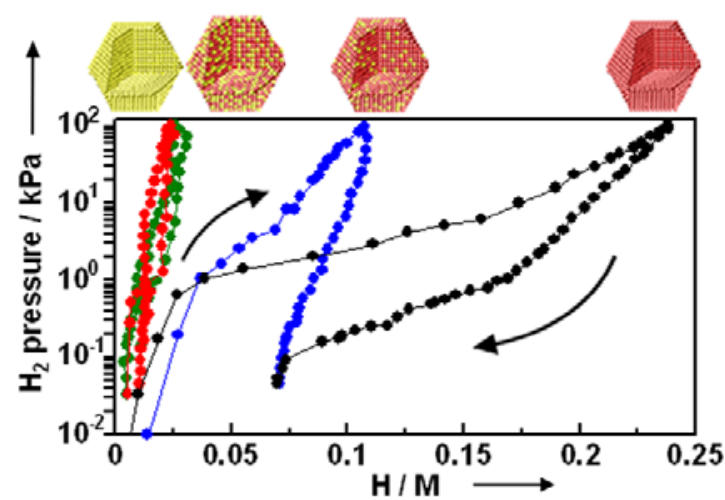

45 Fig. 3 PC isotherms of $\mathrm{Pd}$ (black), $\mathrm{Pd}_{80}-\mathrm{Au}_{20}$ (blue), $\mathrm{Pd}_{50}-\mathrm{Au}_{50}$ (green) and $\mathrm{Au}$ nanoparticles (red). Isotherms were measured according direction of arrows. H/M shows the number of hydrogen atoms divided by the total number of metal.

change of the hydrogen-absorption properties accompanied by 50 the addition of $\mathrm{Au}$ atoms to Pd nanoparticles, PC isotherms of $\mathrm{Pd}-\mathrm{Au}$ nanoparticles were measured at $303 \mathrm{~K}$. As shown in Fig. 3, only 20 at\% replacement of Pd with Au atom results in a reduction of more than half of total amount of hydrogen absorption. With the further addition of $\mathrm{Au}$ atoms, the $\mathrm{Pd}_{50^{-}}$ $55 \mathrm{Au}_{50}$ nanoparticles hardly absorbed hydrogen. It may be expected that the hydrogen concentration in the $\mathrm{Pd}_{50}-\mathrm{Au}_{50}$ nanoparticles is equal to half that of Pd since $\mathrm{Au}$ nanoparticles does not absorb hydrogen. This drastic reduction of hydrogen absorption also indicates that the Pd-Au nanoparticles are not 60 exhibit phase-separation structure but is solid-solution type, where $\mathrm{Pd}$ and $\mathrm{Au}$ atoms are homogeneously mixed at the atomic level. In the desorption process of $\mathrm{Pd}$ and $\mathrm{Pd}_{80}-\mathrm{Au}_{20}$ nanoparticles, the curve does not completely return back to the starting point, indicating that some hydrogen atoms are 65 strongly trapped inside the nanoparticles. ${ }^{12 a}$

It is well known that the hydrogen concentration in Pd bulk is linked to the number of holes in the $4 \mathrm{~d}$ conduction band. ${ }^{13}$ As the 4d conduction band is filled, the hydrogen concentration is reduced. The band-filling effect on hydrogen 70 absorption has been reported in the cases of $\mathrm{Pd}-\mathrm{Ag}^{13 \mathrm{a}, 14}$ and $\mathrm{Pd}-\mathrm{Au}^{15}$ bulk alloys. In our experimental results, the decrease of the hydrogen concentrations originates from the filling up
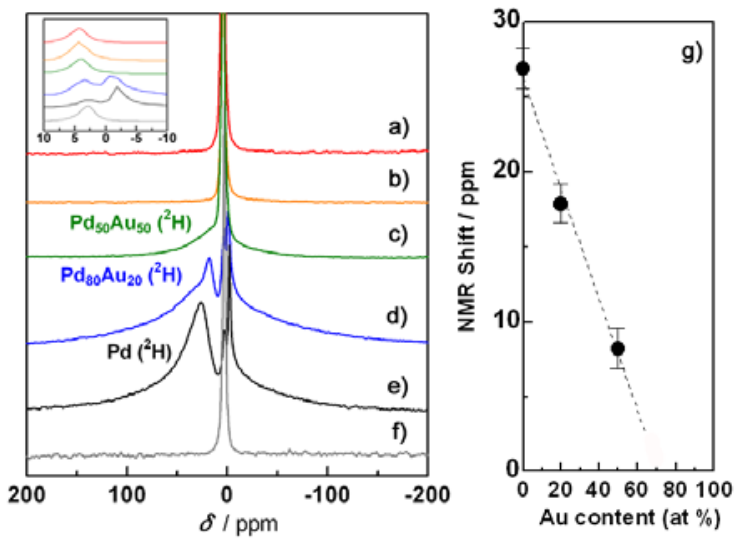

Fig. 4 Solid-state ${ }^{2} \mathrm{H}$ NMR spectra for the samples of Pd-Au nanoparticles at $\mathrm{Pd} / \mathrm{Au}$ ratios = (d) 80/20, (c) 50/50, (b) 20/80. The samples of (f) ${ }^{2} \mathrm{H}_{2}$ 75 gas, (e) Pd and (a) Au nanoparticles were also measured. (g). NMR shift of ${ }^{2} \mathrm{H}$ absorbed inside Pd-Au nanoparticles. 
of the Pd 4d conduction band due to the addition of $\mathrm{Au}$; 6selectron of Au donates to the 4d-band of Pd and the numbers of $4 \mathrm{~d}$ band holes in Pd-Au nanoparticles are decreased. (Fig. S4 in ESI†)

5 Solid-state ${ }^{2} \mathrm{H}$ NMR measurements were performed to investigate the states of ${ }^{2} \mathrm{H}$ in $\mathrm{Pd}-\mathrm{Au}$ nanoparticles (Fig. 4b-d). The sharp line at around $0 \mathrm{ppm}$ and broad absorption lines at a lower field were observed for $\mathrm{Pd}$ and $\mathrm{Pd}-\mathrm{Au}$ nanoparticles with $\mathrm{Au}$ contents of 20 and 50 at\% (Fig. 4c-e)). In the 10 spectrum for ${ }^{2} \mathrm{H}_{2}$ gas, only a sharp line at $3.4 \mathrm{ppm}$ was observed. By comparison of these spectra, it is reasonable to attribute the sharp component in the spectrum of particle to free deuterium gas $\left({ }^{2} \mathrm{H}_{2}\right)$ and the broad component to absorbed deuterium atoms $\left({ }^{2} \mathrm{H}\right)$ (Fig. 4 inset). Additionally, in the 15 spectra for samples of $\mathrm{Pd}$ and $\mathrm{Pd}_{80}-\mathrm{Au}_{20}$ nanoparticles, sharp components were observed at upper field in comparison with the peak position of free ${ }^{2} \mathrm{H}_{2}$ gas, attributing to deuterium atoms diffusing and/or exchanging with free deuterium on the particles surface (Fig. 4 inset). It should be noted that the 20 broad absorption lines, originating from ${ }^{2} \mathrm{H}$ inside the $\mathrm{Pd}-\mathrm{Au}$ lattice, is markedly shifted to upfield linearly with the $\mathrm{Au}$ content (Fig. 4g). This shift implies an increase of the electron density around ${ }^{2} \mathrm{H}$ nuclei, which is caused by change in the occupancies of valence electrons due to hybridization of the 25 valence bands. ${ }^{16}$ This linear shift also demonstrates that atomic-level alloying occurs in Pd-Au system and deuterium in the nanoparticles perceives the different potentials depending on the composition of Pd and Au. Deuterium NMR is, therefore, very sensitive and a powerful probe to the 30 electronic state of nanoparticles.

In summary, we have synthesized and characterized sizecontrolled alloy nanoparticles where $\mathrm{Pd}$ and $\mathrm{Au}$ are homogeneously mixed at the atomic level with a wide range of ratios by the successive reduction method using $\mathrm{H}_{2}$ gas. The 35 atomic-level $\mathrm{Pd}$-Au alloying has been confirmed by means of HRTEM, EDS and XRD measurements. Only 20 at\% of Au in Pd is sufficient to suppress the hydrogen absorption completely. The amount of hydrogen absorption is controllable at lowconcentration alloying with $\mathrm{Au}$ and is considered to depend on 40 the band filling of Pd 4d, which is consistent with the observed linear upfield shift of ${ }^{2} \mathrm{H}$ NMR signal. The atomic-level alloy of variable-size and size-controlled $\mathrm{Pd}-\mathrm{Au}$ nanoparticles are expected to be useful as effective catalysts for various reactions. The present hydrogen reduction method gives us a big advantage 45 for constructing various size-controlled Pd-Au nanoparticles by changing the size of Pd seeds.

\section{Notes and references}

${ }^{a}$ Department of Chemistry, Faculty of Science, Kyushu University, Hakozaki 6-10-1, Fukuoka 812-8581, Japan E-mail:

50 kitagawa@kuchem.kyoto-u.ac.jp; Fax: +75-753-4035; Tel: +75-7534035

${ }^{b}$ JST PRESTO, Sanbancho 5, Chiyoda-ku, Tokyo 102-0075, Japan

c JST CREST, Sanbancho 5, Chiyoda-ku, Tokyo 102-0075, Japan

$\$$ Current address: Department of Biomedical Engineering,

55 Washington University, St. Louis, Missouri 63130, USA,

$\S$ Current address: Catalysis Research Center, Hokkaido University, West 10, North 21, Kita-ku, Sapporo 001-0021, Japan
I Current address: Department of Chemistry, Graduate School of Science, Kyoto University, Kitashirakawa-Oiwakecho, Sakyo-ku, Kyoto 60 606-8502, Japan

† Electronic Supplementary Information (ESI) available: Experimental details, transmission electron microscopy images, electronic spectra, powder x-ray diffraction, schematic view of the density of states. See DOI: $10.1039 / \mathrm{b} 000000 \mathrm{x} /$

65

1 (a) A.-H. Lu, E. L. Salabas, F. Schueth, Angew. Chem., Int. Ed. 2007, 46, 1222; (b) W. S. Seo, et al. Nat. Mater. 2006, 5, 971.

2 (a) V. I Klimov, S. A. Ivanov, J. Nanda, M. Achermann, I. Bezel, J. A. McGuire, A. Piryatinski, Nature 2007, 447, 441; (b) Y. Yang, O.

70 Chen, A. Angerhofer, Y. C. Cao, J. Am. Chem. Soc. 2006, 128, 12428.

3 (a) F. Raimondi, G. G. Scherer, R. Koetz, A. Wokaun, Angew. Chem., Int. Ed. 2005, 44, 2190; (b) J. Schulz, A. Roucoux, H. Patin, Chem. Rev. 2002, 102, 3757.

754 (a) D. Jose, B. R. Jagirdar, J. Phys. Chem. C 2008, 112, 10089; (b) D. Ferrer, A. Torres-Castro, X. Gao, S. Sepúlveda-Guzmn, U. OrtizMéndez, M. José-Yacamn, Nano Lett. 2007, 7, 1701; (c) R. Harpeness, A. Gedanken, Langmuir 2004, 20, 3431; (d) C. Kan, W. Cai, C. Li, L. Zhang, H. Hofmeister, J. Phys. D: Appl. Phys. 2003, 36, 1609.

5 (a) N. Toshima, T. Yonezawa, New J. Chem. 1998, 1179. (b) N. Toshima, M. Harada, Y. Yamazaki, K. Asakurat, J. Phys. Chem. 1992, 96, 9927.

6 (a) Y. H. Chen, Y. H. Tseng, C. S. Yeh, Mater. Chem. 2002, 12, 1419;

85 (b) P. Landon, P. J. Collier, A. F. Carley, D. Chadwick, A. J. Papworth, A. Burrows, C. J. Kiely, G. J. Hutchings, Phys. Chem. Chem. Phys. 2003, 5, 1917 ; (c) A. M. Venezia, V. La Parola, V. Nicoli, G. Deganello, J. Catal. 2002, 212, 56; (d) P. Landon, P. J. Collier, A. J. Papworth, C. J. Kiely,; G. J. Hutchings, Chem. Commun. 2002, 2058; (f) A. Benedetti, L. Bertoldo, P. Canton, G. Goerigk, F. Pinna, P. Riello, S. Polizzi, Catal. Today 1999, 49, 485.

7 (a) J. A. L-Sanchez, N. Dimitratos, P. Miedziak, E. Ntainjua, J. K. Edwards, D. Morgan, A. F. Carley, R. Tiruvalam, C. J. Kiely, G. J. Hutchings Phys. Chem. Chem. Phys., 2008, 10, 1921; (b) J. K. 95 Edwards, G. J. Hutchings, Angew. Chem., Int. Ed. 2008, 47, 9192; (c) A. A. Herzing, A. F. Carley, J. K. Edwards, G. J. Hutchings, C. J. Kiely, Chem. Mater. 2008, 20, 1492; (d) D. Wang, A. Villa, F. Porta, L. Prati, D. S. Su, J. Phys. Chem. C 2008, 112, 8617; (e) D. Wang, A. Villa, F. Porta, D. S. Su, L. Prati, Chem. Commun. 2006, 1956; (f) X. Teng, Q. Wang, P. Liu, W. Han, A. I. Frenkel, W. Wen, N. Marinkovic, J. C. Hanson, J. A. Rodriguez, J. Am. Chem. Soc. 2008, 130, 1093; (g) S. J. Mejía-Rosales, C. Fernández-Navarro, E. Pérez,Tijerina, D. A. Blom, L. F. Allard, M. José-Yacamán, J. Phys. Chem. C 2007, 111, 1256.

1058 V. I. Pârvulescu, V. Pârvulescu, U. Endruschat, G. Filoti, F. E. Wagner, C. Kübel, R. Richards, Chem. Eur. J. 2006, 12, 2343.

9 T. Teranishi, M. Miyake, Chem. Mater. 1998, 10, 594.

10 C. H. Chen, L. S. Sarma, J. M. Chen, S. C. Shih, G. R. Wang, D. G. Liu, M. T. Tang, J. F. Lee, B. J. Hwang, ACS Nano, 2007, 1, 114.

11011 (a) Y. Fukaia, Y. Ishiib, Y. Gotoc, K. Watanabed, J. Alloys Compd. 2000, 313, 121; (b) Y. Fukai, J. Alloys Compd. 2003, 356-357, 263; (c) Y. Fukai, H. Sugimoto, J. Phys.: Condens. Matter 2007, 19, 436201.

12 (a) H. Kobayashi, M. Yamauchi, H. Kitagawa, Y. Kubota, K. Kato, 115 M. Takata, J. Am. Chem. Soc. 2008, 130, 1818; (b) H. Kobayashi, M. Yamauchi, H. Kitagawa, Y. Kubota, K. Kato, M. Takata, J. Am. Chem. Soc. 2008, 130, 1828; (c) M. Yamauch, R. Ikeda, H. Kitagawa, M. Takata, J. Phys. Chem. C 2008, 112, 3294.

13 (a) E. Wicke, J. Less-Common Met. 1984, 101, 17; (b) D.A. 120 Papaconstantopoulos, B.M. Klein, E.N. Econoumov, C.C. Boyer, Phys. Rev. B 1979, 17, 141.

14 A.K.M. F. Kibria, Y. Sakamoto, Int. J. Hydrogen Energy 2000, 25, 853.

15 (a) A. Maeland, T. B. Flanagan, J. Phys. Chem. 1965, 69, 3575. (b) N. 125 Mott, H. Jones, "Theory of Metals and Alloys," Clarendon Press, Oxford 1936.

16 Nascente, P.A.P.; de Castro, S.G.C.; Landers, R.; Kleiman, G.G. Phys. Rev.1991-II, 43, 4659. 